\title{
Inter-calibration of polar imager solar channels using SEVIRI
}

\author{
J. F. Meirink ${ }^{1}$, R. A. Roebeling ${ }^{2}$, and P. Stammes ${ }^{1}$ \\ ${ }^{1}$ Climate Observations Department, Royal Netherlands Meteorological Institute (KNMI), De Bilt, the Netherlands \\ ${ }^{2}$ User Support and Climate Services Department, EUMETSAT, Darmstadt, Germany \\ Correspondence to: J. F. Meirink (meirink@knmi.nl)
}

Received: 6 February 2013 - Published in Atmos. Meas. Tech. Discuss.: 3 April 2013

Revised: 18 July 2013 - Accepted: 14 August 2013 - Published: 26 September 2013

\begin{abstract}
Accurate calibration of satellite imagers is a prerequisite for using their measurements in climate applications. Here we present a method for the inter-calibration of geostationary and polar-orbiting imager solar channels based on regressions of collocated near-nadir reflectances. Specific attention is paid to correcting for differences in spectral response between instruments. The method is used to calibrate the solar channels of the Spinning Enhanced Visible and Infrared Imager (SEVIRI) on the geostationary Meteosat satellite with corresponding channels of the Moderate Resolution Imaging Spectroradiometer (MODIS) on the polar-orbiting Aqua satellite. The SEVIRI operational calibration is found to be stable during the years 2004 to 2009 , but offset by $-8,-6$, and $+3.5 \%$ for channels $1(0.6 \mu \mathrm{m}), 2(0.8 \mu \mathrm{m})$, and $3(1.6 \mu \mathrm{m})$, respectively. These results are robust for a range of choices that can be made regarding data collocation and selection, as long as the viewing and illumination geometries of the two instruments are matched. Uncertainties in the inter-calibration method are estimated to be $1 \%$ for channel 1 and $1.5 \%$ for channels 2 and 3 . A specific application of our method is the inter-calibration of polar imagers using SEVIRI as a transfer instrument. This offers an alternative to direct inter-calibration, which in general has to rely on high-latitude collocations. Using this method we have tied MODIS-Terra and Advanced Very High Resolution Radiometer (AVHRR) instruments on National Oceanic and Atmospheric Administration (NOAA) satellites 17 and 18 to MODIS-Aqua for the years 2007 to 2009. While reflectances of the two MODIS instruments differ less than $2 \%$ for all channels considered, deviations of an existing AVHRR calibration from MODIS-Aqua reach -3.5 and $+2.5 \%$ for the 0.8 and $1.6 \mu \mathrm{m}$ channels, respectively.
\end{abstract}

\section{Introduction}

Over the past decades, many different meteorological imaging instruments have been installed in space on board of polar and geostationary satellites. Initially intended for qualitative imagery, these instruments have increasingly also been used for the quantitative retrieval of atmospheric and surface properties. With the latter application and the demand for stable time series, accurate calibration of the measured radiances has become essential. This holds in particular for the solar channels, which often lack on-board calibration facilities.

In general, two in-flight calibration approaches can be distinguished: (1) using well-characterised targets in combination with radiative transfer modelling to simulate the imager radiances or (2) comparing with radiances measured by other satellite or aircraft instruments. In the first approach a wide range of targets, including deserts, ice caps, deep convective clouds, and the moon, can be used as a reference (e.g. Vermote and Kaufman, 1995; Smith et al., 2002; Heidinger et al., 2003; Govaerts et al., 2004; Doelling et al., 2013a). While this is a powerful method, and the only option for the early imager era, it does have limitations, notably the assumed stability of the reflectivity of the targets and uncertainties due to variations in the atmospheric conditions (trace gases and aerosols). Furthermore, no single target type can be applied over the full range of satellite instruments (geostationary and polar orbiting) and solar channels.

The second approach, inter-calibration of satellite instruments, is normally based on simultaneous nadir overpasses (SNOs) for which near-nadir, collocated radiances are collected, without the need for specific target selection. SNOs have been applied both to pairs of polar imagers (e.g. Minnis et al., 2002, 2008; Heidinger et al., 2002, 2010; Cao et al., 2008 ) and polar-geostationary instrument combinations (e.g. 
Minnis et al., 2002; Roebeling et al., 2006; Ham and Sohn, 2010). Although this method is not hampered by some of the limitations of the "target" approach, it does require consensus on a well-calibrated reference instrument. The Moderate Resolution Imaging Spectroradiometer (MODIS) instruments onboard the Terra and Aqua platforms appear to be good candidates given their on-board calibration devices (Xiong and Barnes, 2006).

In this paper, an SNO method for polar-geostationary imager solar channel inter-calibration is presented. An important requirement for such a method is that differences in spectral response functions (SRFs) between the imagers are taken into account. Recently, Doelling et al. (2013b) employed Scanning Imaging Absorption Spectrometer for Atmospheric Cartography (SCIAMACHY) hyperspectral radiances for this purpose. Here, we use radiative transfer calculations to estimate pixel-by-pixel SRF corrections. The method is applied to calibrate the three solar channels of the geostationary Spinning Enhanced Visible and Infrared Imager (SEVIRI) on Meteosat with MODIS-Aqua. The sensitivity of the results to assumptions underlying the method, including collocation, sampling, and viewing/illumination geometry selection criteria, is assessed.

Direct inter-calibration of polar-orbiting sensors usually has to rely on SNOs at high latitudes. Potential drawbacks of these SNOs are a limited dynamic range of measured radiances and problems in characterising scenes over bright snow- or ice-covered surfaces. Similar to Wang et al. (2011), who applied double differencing to inter-calibrate infrared radiances of two polar-orbiting sounders, we explore the use of the SEVIRI instrument to transfer calibrations from one polar imager to another. In this way, MODIS-Terra as well as two Advanced Very High Resolution Radiometers (AVHRRs) are tied to MODIS-Aqua. In particular, the AVHRR calibration by Heidinger et al. (2010), which is based on direct SNOs, will be verified.

The work described here is closely linked to the Global Space-based Inter-Calibration System (GSICS) effort (Goldberg et al., 2011), which aims to monitor, improve and harmonize the quality of observations from operational weather and environmental satellites.

The setup of this paper is as follows. The measurements are introduced in Sect. 2. Then the calibration approach is outlined in Sect. 3. Results of the inter-calibration of SEVIRI and MODIS are presented in Sect. 4, followed by a sensitivity analysis in Sect. 5. Section 6 describes the use of the method for polar imager inter-calibration. Conclusions are finally drawn in Sect. 7.

\section{Measurements}

This section starts with some definitions and notation of solar channel measurements, after which information is provided on the three satellite instruments that are considered in this paper: SEVIRI, MODIS, and AVHRR.

\subsection{Terminology}

The calibration of satellite imager solar channels centres around the determination of the calibration slope $S$ and dark count $D$ in the relation

$I=S(C-D)$,

where $C$ is the measured count and $I$ is the radiance in the direction of the satellite in a specific channel. The units of $I$ and $S$ used here are $\mathrm{W} \mathrm{m}^{-2} \mathrm{sr}^{-1} \mu \mathrm{m}^{-1}$. $I$ is obtained by integrating the spectral radiance $I_{\mathrm{s}}(\lambda)$ weighted by the instrument spectral response function (SRF), $\xi(\lambda)$, over wavelength $\lambda$ :

$I=\frac{\int \xi(\lambda) I_{\mathrm{s}}(\lambda) \mathrm{d} \lambda}{\int \xi(\lambda) \mathrm{d} \lambda}$.

The reflectance $R$ is then defined as:

$R=\frac{\pi I}{E_{0} \cos \theta_{0}}$,

where $E_{0}$ is the extra-terrestrial solar irradiance perpendicular to the solar beam contained within the channel's SRF in $\mathrm{W} \mathrm{m}^{-2} \mu \mathrm{m}^{-1}$, and $\theta_{0}$ is the solar zenith angle at the surface. The calibration results in this paper will be based on comparing measured reflectances, but we will also use the sun-normalised radiance $R_{\mathrm{n}}$ in a few occasions:

$R_{\mathrm{n}}=R \cos \theta_{0}$.

\subsection{Instruments}

SEVIRI is a 12-channel imager on the Meteosat Second Generation (MSG) geostationary satellites operated by the European Organization for the Exploitation of Meteorological Satellites (EUMETSAT). Three of a planned total of four MSG satellites, Meteosat-8, -9 , and -10 , have been launched to date. Apart from one high-resolution visible (HRV) channel, SEVIRI carries 11 channels between 0.6 and $14 \mu \mathrm{m}$ with a resolution of $3 \times 3 \mathrm{~km}^{2}$ at nadir and a $15 \mathrm{~min}$ repeat cycle. This study focuses on the short-wave channels 1, 2, and 3, for which spectral information is provided in Table 1. SEVIRI is not equipped with an on-board calibration device for these channels. An operational vicarious calibration algorithm relying on desert and ocean targets (Govaerts and Clerici, 2004; Govaerts et al., 2004) was put in place by EUMETSAT for the Meteosat Visible and Infrared Imager (MVIRI) originally, and has been carried over to SEVIRI. However, this operational calibration was shown to considerably deviate from MODIS for channel 1 (Doelling et al., 2004; Ham and Sohn, 2010). 
Table 1. Channel numbers and central wavelengths $\lambda_{c}$ of the solar channels considered in this study together with the approximate wavelengths used for reference.

\begin{tabular}{|c|c|c|c|c|c|c|}
\hline \multirow[b]{2}{*}{ Instrument } & \multicolumn{2}{|c|}{$\mathrm{ch} 1,0.6 \mu \mathrm{m}$} & \multicolumn{2}{|c|}{$\operatorname{ch} 2,0.8 \mu \mathrm{m}$} & \multicolumn{2}{|c|}{$\operatorname{ch} 3,1.6 \mu \mathrm{m}$} \\
\hline & channel & $\lambda_{\mathrm{c}}(\mu \mathrm{m})$ & channel & $\lambda_{\mathrm{c}}(\mu \mathrm{m})$ & channel & $\lambda_{\mathrm{c}}(\mu \mathrm{m})$ \\
\hline SEVIRI & 1 & 0.635 & 2 & 0.810 & 3 & 1.640 \\
\hline MODIS & 1 & 0.645 & 2 & 0.858 & 6 & 1.640 \\
\hline AVHRR & 1 & 0.630 & 2 & 0.865 & $3 a$ & 1.610 \\
\hline
\end{tabular}

MODIS is a cross-track-scanning imager on the polarorbiting National Aeronautics and Space Administration's (NASA) Earth Observing System (EOS) platforms Terra and Aqua. It measures radiation from 0.4 to $14.5 \mu \mathrm{m}$ in $36 \mathrm{spec}-$ tral channels. Considerable efforts have been devoted to the calibration and characterisation of the MODIS instrument, taking advantage of the on-board calibration facilities (Xiong and Barnes, 2006). From the two MODIS instruments the one on Aqua has proven to be the most stable, as the MODIS-Terra solar diffuser door has been kept permanently in an open position since July 2003 (Wu et al., 2013). Thus, MODIS-Aqua is considered here as the reference for the other sensors. The uncertainty of MODIS reflectance for the solar channels under consideration is estimated to be less than 2\% (Xiong et al., 2005). In this study, MODIS radiances at 1-km spatial resolution, (the MOD021KM and MYD021KM collection 5 products) have been used. Of interest are channels 1,2, and 6 (see Table 1), as well as channels 17 and 18 near $0.94 \mu \mathrm{m}$ to characterise atmospheric water vapour (see Sect. 3).

AVHRR is an imager flown on the Polar-orbiting Operational Environmental Satellite (POES) series of National Oceanic and Atmospheric Administration (NOAA) satellites since 1978, as well as on the EUMETSAT Metop series since 2006. With continued planned extension until at least 2018, the AVHRR record will span over $40 \mathrm{yr}$ and is thus very valuable for climate studies. In this study, the AVHRR/3 instrument comprising 6 channels between 0.6 and $12 \mu \mathrm{m}$ is considered. The inter-calibration is done for channels 1,2 , and 3a, the latter of which was only active on some of the NOAA satellites. AVHRR nominal observations are taken at $1 \mathrm{~km}$ spatial resolution, but aggregated to $3 \times 5 \mathrm{~km}^{2}$ for global area coverage (GAC) transmittance to the ground. AVHRR lacks an on-board calibration device, but extensive efforts have been dedicated to post-launch calibration. Heidinger et al. (2010) developed a calibration approach based on SNOs as well as Antarctic and desert targets, which was radiometrically tied to MODIS. That approach includes a conversion of the measured AVHRR/3 dual-gain count to what a single-gain count would have been.

The starting point of this paper are existing reference calibrations of the three instruments. For MODIS the collection 5 calibration as provided in the MOD02/MYD02 files is used. For AVHRR we use the Heidinger et al. (2010) cali- bration. For SEVIRI the operational calibration by EUMETSAT is used. The EUMETSAT operational calibration coefficients, which are reported in the SEVIRI level-1b files, are constant except for one stepwise change on the order of $1 \%$ during the investigated time periods for Meteosat8 and -9 . To avoid artificial jumps in our inter-calibration results and to keep direct traceability to the instrument counts, we have chosen to use the calibration coefficients of January 2007 as the reference for both satellites. These are $S=0.5736,0.4531$, and $0.08783 \mathrm{~W} \mathrm{~m}^{-2} \mathrm{sr}^{-1} \mu \mathrm{m}^{-1}$ for Meteosat- 8 channels 1, 2, and 3, respectively, and $S=0.4993$, 0.3951 , and $0.08276 \mathrm{~W} \mathrm{~m}^{-2} \mathrm{sr}^{-1} \mu \mathrm{m}^{-1}$ for Meteosat- 9 channels 1,2 , and 3, respectively. In addition, values of $E_{0}$ as provided by EUMETSAT are used to convert SEVIRI radiances to reflectances (see http://www.eumetsat.int/groups/ ops/documents/document/pdf_msg_seviri_rad2refl.pdf).

The calibration of SEVIRI (SEV) with respect to a polarorbiting imager $(\mathrm{P})$ will be expressed in terms of an intercalibration slope $s$ :

$s_{\mathrm{SEV} / \mathrm{P}}=\left\langle\frac{R_{\mathrm{SEV}}}{R_{\mathrm{P}}}\right\rangle$,

where the mean reflectance ratio is in practice determined by a linear fit. In practice, MODIS-Aqua will be taken as the reference instrument $P$. The inter-calibration slope can then be used to calculate a corrected calibration slope $S^{*}$ for SEVIRI:

$S_{\mathrm{SEV}}^{*}=S_{\mathrm{SEV}} / s_{\mathrm{SEV} / \mathrm{P}}$.

Instrument dark counts $D$ are assumed to be correct as provided. This assumption will be verified by performing both free linear calibration fits as well as fits forced through the origin.

In this study, six years (2004 to 2009) of SEVIRI-Meteosat and MODIS-Aqua data are considered. In addition, three years (2007 to 2009) of data from other polar imagers are evaluated. These time periods are long enough to make statements about the stability of the calibration of the respective satellite instruments, and in some cases sufficient to calculate significant trends in inter-calibration coefficients. 


\section{Method}

Our calibration method consists of the following steps:

1. Collect SEVIRI and polar imager near-nadir reflectances near the SEVIRI sub-satellite point and with the smallest possible time difference. Given the SEVIRI repeat cycle of $15 \mathrm{~min}$, the time difference is about $7.5 \mathrm{~min}$ at most.

2. Convert SEVIRI reflectances to the spectral response of the polar imager by correcting for within-band atmospheric transmissivity.

3. Aggregate reflectances to a common regular latitudelongitude grid. A $0.15^{\circ} \times 0.15^{\circ}$ grid was used for the MODIS-SEVIRI comparisons, while for the AVHRR-SEVIRI comparisons a somewhat larger $\left(0.25^{\circ} \times 0.25^{\circ}\right)$ grid was chosen because of the larger AVHRR pixel size.

4. Generate a subset of the reflectance pairs based on viewing/illumination geometry and possibly other selection criteria.

5. Perform a linear regression of SEVIRI against polar imager reflectances. Since there is no true independent variable we apply orthogonal fits, i.e. least squares fits based on the orthogonal distance of reflectance pairs to the fit line. The regression yields an inter-calibration slope.

We will first outline the SRF correction approach applied in step 2. Then the method is illustrated with a concrete example.

\subsection{Correcting for differences in spectral response}

The spectral response functions of the relevant SEVIRI, MODIS, and AVHRR channels around 0.6, 0.8, and $1.6 \mu \mathrm{m}$ are shown in Fig. 1, together with the atmospheric transmissivity spectrum. The MODIS channels are generally narrower and less affected by atmospheric gas absorption than the SEVIRI and AVHRR channels. The AVHRR channel 2 is much broader than the others. These differences need to be taken into account before measured reflectances can be compared, which is done by the following procedure.

The impact of the SRF on the observed reflectance can be divided into two components. The first component is related to spectral variations in the albedo of the (land/ocean/cloud) scene, the second to spectral variations in atmospheric gas absorption. In this study, only the second component is considered, i.e. the SRF correction is essentially an atmospheric correction. We assume the reflectance of the scene to be spectrally uniform within the wavelength bands considered. However, the reflectance of, in particular, land surfaces is characterised by considerable spectral variations in some wavelength regions. The sensitivity analysis in Sect. 5 includes
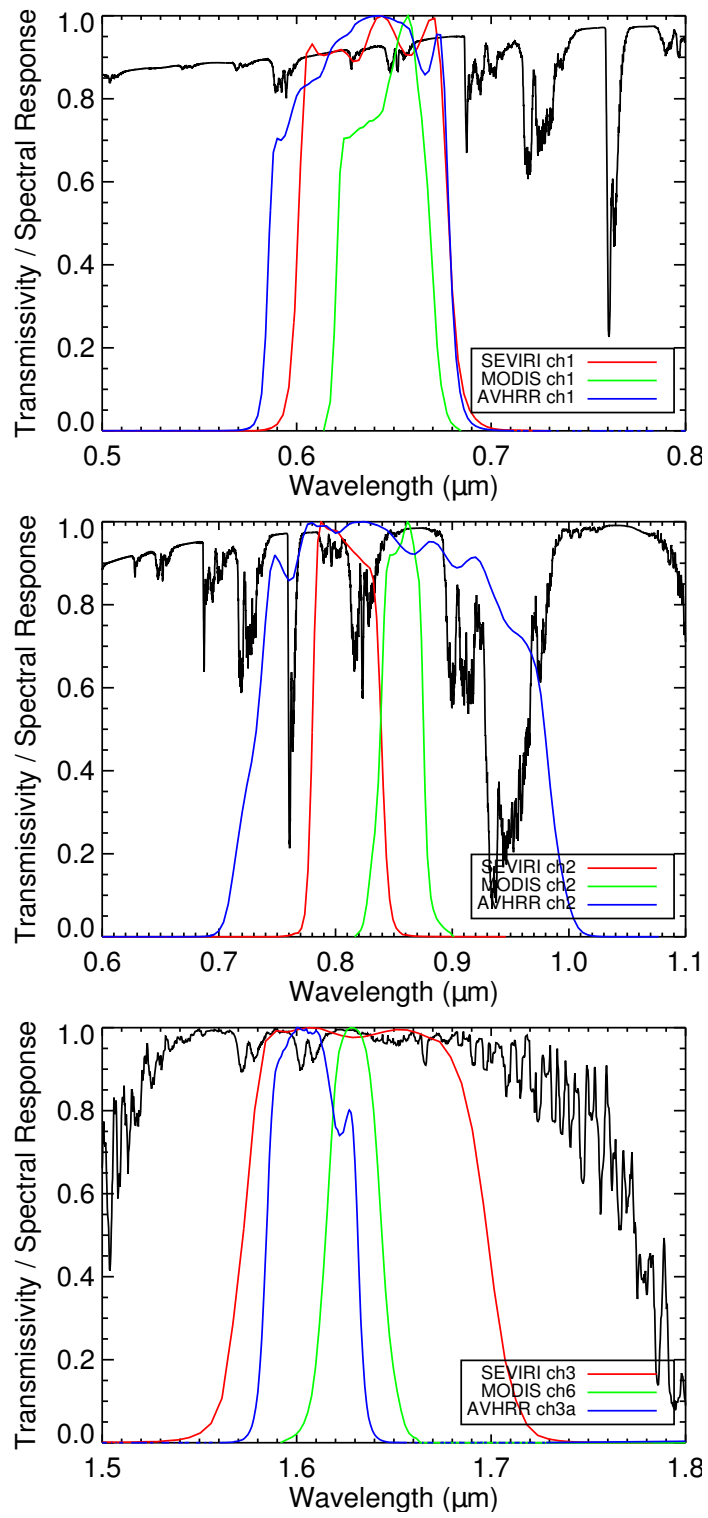

Fig. 1. Spectral response functions of SEVIRI, MODIS and AVHRR for the three solar channels considered in this paper, as obtained from http://www.eumetsat.int/Home/Main/ Satellites/MeteosatSecondGeneration/Instruments/index.htm, ftp:// mcst.hbsss-sigma.com/pub/permanent/MCST, and http://www2. ncdc.noaa.gov/docs $/ \mathrm{klm} / \mathrm{html} / \mathrm{d} / \mathrm{app}$-d.htm, respectively. A nadir transmissivity spectrum calculated with MODTRAN and based on a tropical atmosphere (McClatchey et al., 1971) is shown in black.

inter-calibrations based on pixels over land and ocean separately (instead of over land and ocean combined) in order to assess the potential error due to the assumption of spectrally uniform reflectance.

We used the Moderate Resolution Atmospheric Transmission code (MODTRAN4 Version 2; Anderson et al., 2001) to simulate top-of-atmosphere (TOA) reflectance spectra over the satellite instrument wavelength bands, including 
Rayleigh scattering and absorption by atmospheric gases, for a Lambertian surface with fixed surface albedo. Note that the actual value of the surface albedo, here set to 0.35 , is not important since we are considering only ratios of TOA reflectance for different SRFs (see below). Clouds were not explicitly taken into account, but were modelled by placing the surface at the height of the cloud top, $H_{\mathrm{c}}$. Apart from $H_{\mathrm{c}}$ the reflectance depends on the solar zenith angle $\left(\theta_{0}\right)$, the satellite zenith angle $(\theta)$, and the above-cloud partial column amounts of atmospheric trace gases. While some of the relevant absorbing gases, $\mathrm{O}_{2}, \mathrm{CO}_{2}$, and $\mathrm{CH}_{4}$, are long-lived and therefore well-mixed in the atmosphere, water vapour and to a lesser extent - ozone are characterised by considerable horizontal and vertical variations. Since ozone largely resides in the stratosphere, it was assumed that all ozone is above the clouds. For water vapour a fixed vertical profile (McClatchey et al., 1971) was used to determine its above-cloud column. The illumination and viewing geometry were combined in the geometrical air-mass factor $\left(\mathrm{AMF}=1 / \cos \theta_{0}+1 / \cos \theta\right)$, which is proportional to the length of the light path. Reflectances $R^{\mathrm{sim}}$ were then simulated with MODTRAN for the various instrument channel SRFs following Eqs. (2)-(3), and stored in a look-up table as a function of four variables: $H_{\mathrm{c}}$, AMF, total column ozone (TCO) and total column water vapour (TCWV).

For each satellite pixel measurement, actual values of these four variables thus need to be determined. $H_{\mathrm{c}}$ was retrieved from $11 \mu \mathrm{m}$ SEVIRI radiances using the approach outlined by Roebeling and Holleman (2009). This $H_{\mathrm{c}}$ can be regarded as the effective infrared radiating height rather than the physical cloud-top height, and is thus consistent with the placement of a Lambertian surface at $H_{\mathrm{c}}$ in the MODTRAN simulations. TCO was taken from a monthly mean climatology at $1^{\circ} \times 1.5^{\circ}$ (lat-lon) derived from the Multi Sensor Reanalysis (MSR) dataset by Van der A et al. (2010). TCWV was taken from a monthly-mean climatology at $1^{\circ} \times 1^{\circ}$ derived from the ERA-Interim reanalysis (Dee et al., 2011). These assumptions constitute potential sources of error, especially in channel 2 which is characterised by strong water vapour absorption. This will be further discussed below. In our spectral response correction procedure, for each SEVIRI pixel with measured reflectance $R_{\mathrm{SEV}}$, the reflectance $R_{\mathrm{SEV}}^{\prime}$ that would have been observed given the SRF of a polar imager (MODIS or AVHRR) is estimated as:

$$
R_{\mathrm{SEV}}^{\prime}=R_{\mathrm{SEV}} \frac{R_{\mathrm{P}}^{\mathrm{sim}}}{R_{\mathrm{SEV}}^{\operatorname{sim}}}
$$

where $R_{\mathrm{SEV}}^{\text {sim }}$ and $R_{\mathrm{P}}^{\mathrm{sim}}$ are the MODTRAN-simulated reflectances for the SEVIRI and polar-orbiter channels, respectively. More details on the atmospheric correction method can be found in Meirink et al. (2009).

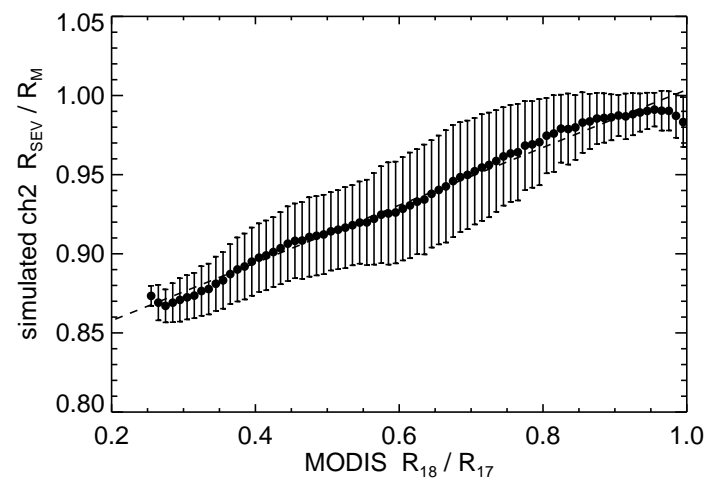

Fig. 2. Relation between simulated SEVIRI to MODIS reflectance ratio in channel $2(0.8 \mu \mathrm{m})$ and MODIS ch18/ch17 reflectance ratio, demonstrating the water vapour correction capability in our SRF correction procedure. Circles show the mean and vertical bars the standard deviation of simulated ch2 reflectance ratio in a MODIS ch18/ch17 reflectance ratio bin. The figure is based on about 200000 data points from the year 2008. The correlation coefficient of the underlying individual data points is 0.77 .

The SRF correction procedure has various sources of uncertainty, e.g. from potential errors in the $H_{\mathrm{c}}$ and trace-gas amount input used, and in the accounting for below-cloud absorption in broken and semi-transparent cloud scenes. Uncertainties are largest for channel 2 , in which considerable absorption by atmospheric water vapour takes place. Fortunately, MODIS carries additional channels that can be used to validate the SRF correction. MODIS channels 18 and 17 are situated inside and mainly outside the $0.94 \mu \mathrm{m}$ water vapour absorption band, respectively. As a result, the ratio of channel 18 to 17 reflectances is inversely proportional to the amount of water vapour above the clouds (Heidinger et al., 2002). Figure 2 shows the relation between the simulated MODIS-SEVIRI ch2 reflectance ratio and the MODIS ch18/ch17 reflectance ratio. These quantities should be strongly correlated since water vapour is the main absorber in channel 2. Indeed, a good linear correlation is obtained, which validates the water vapour correction both for clear and cloudy pixels. This also gives confidence in the atmospheric correction method for other sensors, such as AVHRR, that do not carry the suitable channels for the determination of atmospheric water vapour columns in both clear and cloudy conditions.

\subsection{Illustration of the method}

The inter-calibration procedure is illustrated in Fig. 3. For a given MODIS-Aqua granule, the corresponding SEVIRI image is acquired. SEVIRI reflectances are then converted to the MODIS spectral response function, and reflectances from both instruments are aggregated to the same equal-angle grid. A scatter density plot of all grid cells, shown in the lower left of Fig. 3, indicates a strong correlation between the 

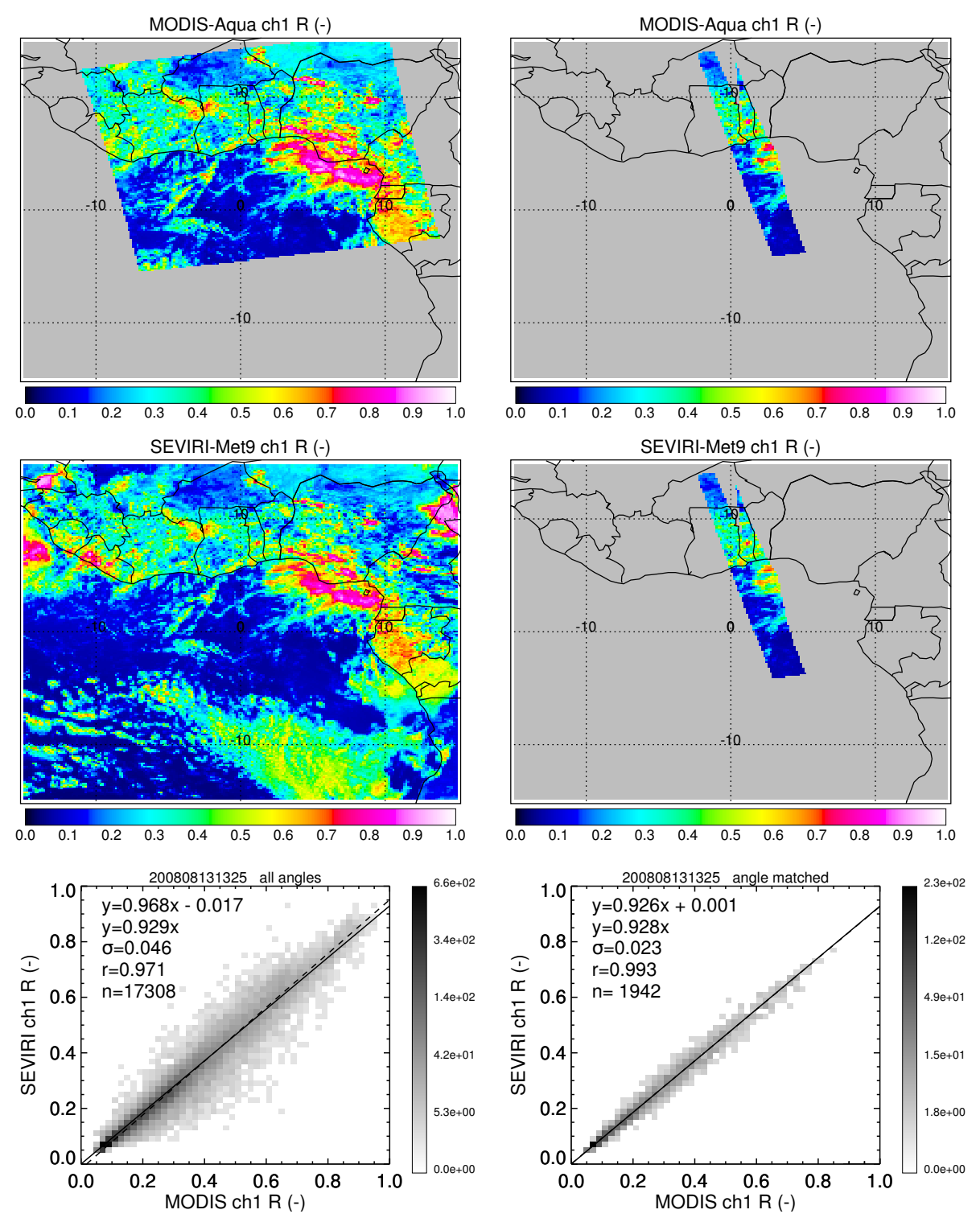

Fig. 3. Illustration of the calibration approach for a MODIS-Aqua granule on 13 August 2008 between 13:25 and 13:30 UTC and a SEVIRI image around 13:21 UTC. The top row shows MODIS ch1 reflectance, and the middle row shows SEVIRI ch1 reflectance corrected to the MODIS SRF using Eq. (7). The bottom row shows scatter density plots between SEVIRI and MODIS $R$ in which the free linear fit (dashed) and the linear fit through the origin (solid) are indicated. A cubic colour scale, as indicated by the vertical bars, has been used to make the low densities visible. Fit statistics including the standard deviation relative to the fit line $(\sigma)$, the Pearson correlation coefficient $(r)$, and the number of grid cells $(n)$ are listed. The left panels are for all available data, while the right panels are restricted to those grid cells satisfying the standard geometric selection criteria.

reflectances, but the slopes of the best linear fit and a linear fit through the origin differ considerably. This is typical, and it is mainly a consequence of not having applied viewing and illumination geometry selection criteria to ensure that the photons reaching both instruments have travelled a nearly equal light path. This so-called ray-matching (e.g. Doelling et al., 2004 ), is reached by requiring the differences in $\theta_{0}, \theta$, and scattering angle $\Theta$ between collocated pixels to be smaller than a specific limit, here chosen as $10^{\circ}$. Note that for $\theta_{0}$ this requirement is automatically fulfilled by the spatio-temporal collocation between the instruments. After the application of these criteria only a fraction of the data is retained, but these typically yield a significantly higher correlation as well as a much improved consistency between the two fit types (see lower right panel of Fig. 3).

Since the number of pixels selected for the fits varies a lot from granule to granule, the granule-based fit results are relatively noisy. Therefore, fits are performed for the collection 

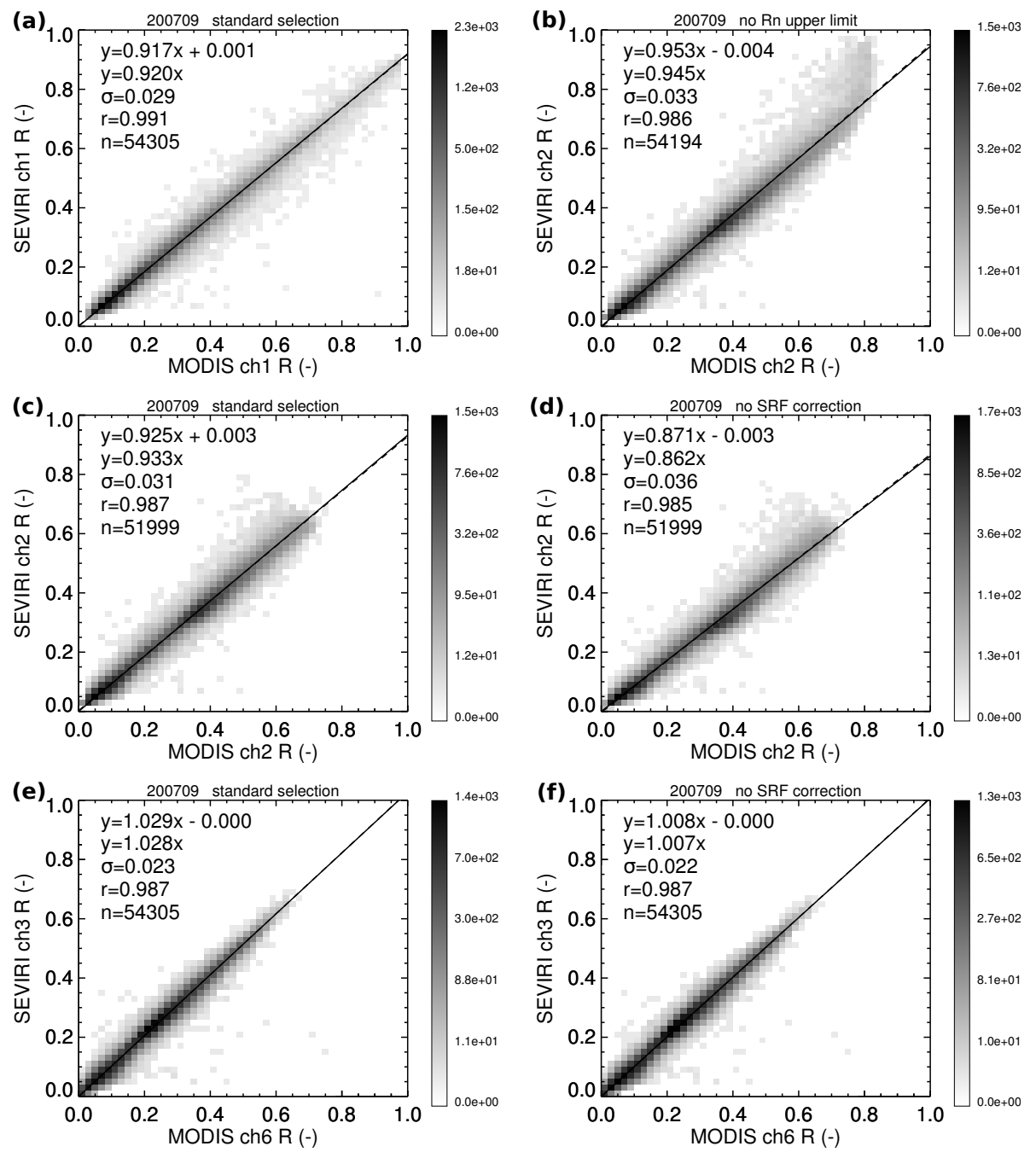

Fig. 4. Monthly (September 2007) fits of SEVIRI-Meteosat-9 against MODIS-Aqua reflectances: (a) channel 1, (b) channel 2 without upper limit to $R_{\mathrm{n}}$, (c) channel 2 with upper limit to $R_{\mathrm{n}}$ (this is the standard setting for channel 2; see text), (d) channel 2 without SRF correction, (e) channel 3, (f) channel 3 without SRF correction. For all fits the standard geometric selection criteria have been applied. The free linear fits (dashed) and linear fits through the origin (solid) are indicated in the plots. A cubic colour scale, as indicated by the vertical bars, has been used to make the low densities visible.

of all data in a month. We collected all MODIS-Aqua granules near $\left(0^{\circ} \mathrm{W}, 0^{\circ} \mathrm{N}\right)$, the Meteosat-9 sub-satellite point, usually one or two per day. Scatter plots of ray-matched reflectance pairs for channels 1 to 3 from all granules in a selected month (September 2007) are shown in Fig. 4. The correlations are generally very high and the two types of linear fits are consistent. The highest correlations are obtained for channel $1(0.6 \mu \mathrm{m})$, probably because there is very little absorption by trace gases in this channel, so that the SRF correction is almost negligible. In addition, the dynamic range is high, enabling more robust fits. For channel $2(0.8 \mu \mathrm{m}) \mathrm{a}$ complicating feature is observed (Fig. 4b): the MODIS channel saturates around a value of the sun-normalised radiance of about $0.7-0.75$, because it has been optimised for landsurface applications. While individual saturated pixels could have been filtered out directly from the 250-m MODIS level$1 \mathrm{~b}$ product, this is not possible for aggregated $1-\mathrm{km}$ pixels in the post-processed 1-km level-1b files that we used, in case these pixels partly consist of saturated $250-\mathrm{m}$ pixels. Indeed, the impact of saturation is clearly visible in Fig. 4b, resulting in an overestimate of the slope. To take care of this issue, only $R_{\mathrm{n}}$ pairs with an average value less than 0.6 are considered for the regressions further on (see Fig. 4c), giving somewhat lower regression slopes. Figure $4 \mathrm{~d}$ shows what happens if the reflectances are not corrected for SRF differences. Since the SEVIRI channel 2 is much more affected by trace gas absorption (in particular of water vapour) than the MODIS channel 2, the SRF correction leads to an increase in the slope of about $7 \%$. SRF correction typically also yields a slightly improved correlation between the reflectance pairs. 
Fit results for channel $3(1.6 \mu \mathrm{m})$ with and without SRF correction are presented in Fig. 4e and f, respectively. For this channel the effect of SRF correction is about $2 \%$. A significant number of $1.6 \mu \mathrm{m}$ detectors on MODIS-Aqua are defective, causing stripes in the $1 \mathrm{~km}$ level-1b images. Despite of this, we have applied the usual aggregation procedure, still finding sufficient valid pixels in the $0.15^{\circ} \times 0.15^{\circ}$ grid cells. The inter-calibration does not appear to suffer from the missing MODIS pixels. In all scatter plots a concentration of points at low reflectance values can be observed. These points largely correspond to clear-sky ocean pixels. The reflectance of clear-sky land varies between the channels, with low values for channel 1 , higher values $(\sim 0.2$ to 0.3$)$ for channel 3 , and the highest values $(\sim 0.3$ to 0.4$)$ for channel 2. Indeed, in the scatter plots for channel 2, two concentrations of reflectance pairs are visible, corresponding to clear-sky ocean and land.

In the remainder, a "standard" pixel selection configuration will be used to generate calibration regression statistics. This configuration includes all pixels with $\Delta \theta_{0}<10^{\circ}$, $\Delta \theta<10^{\circ}$, and $\Delta \Theta<10^{\circ}$, as well as an $R_{\mathrm{n}}$ limit of 0.6 for channel 2 as explained above. Sensitivities to other selection configurations will be assessed in Sect. 5 .

\section{Inter-calibration of SEVIRI and MODIS}

The method has been applied to three years (April 2004 to March 2007) of collocated MODIS-Aqua and SEVIRIMeteosat- 8 reflectances and three years (January 2007 to December 2009) of collocated MODIS-Aqua and SEVIRIMeteosat-9 reflectances. Time series of monthly intercalibration slopes for the three solar channels are displayed in Fig. 5. These are the slopes of the linear fits through the origin, both for observed and SRF-corrected SEVIRI reflectances, and based on the standard geometric selection criteria.

For channel 1, inter-calibration slopes around 0.92 are found for both Meteosats. Since MODIS-Aqua is considered to be the reference instrument, this means that the SEVIRI reflectance following from the operational EUMETSAT calibration is about $8 \%$ too low. This result is consistent with earlier findings by Doelling et al. (2004) and Ham and Sohn (2010). The calibration method gives very stable month-to-month slopes, with a standard deviation relative to the trend line of about 0.004 . The correlation between SEVIRI and MODIS is high for all months and shows very little temporal variation (not shown). The impact of the spectral response correction, quantified by the difference between red and black symbols/curves, is negligible for this channel, because there is little absorption by trace gases. In contrast, for channel 2 the difference in SRFs between the two instruments has a much larger effect: SEVIRI is more affected by water vapour absorption than MODIS. The impact of this absorption is different for every individual scene
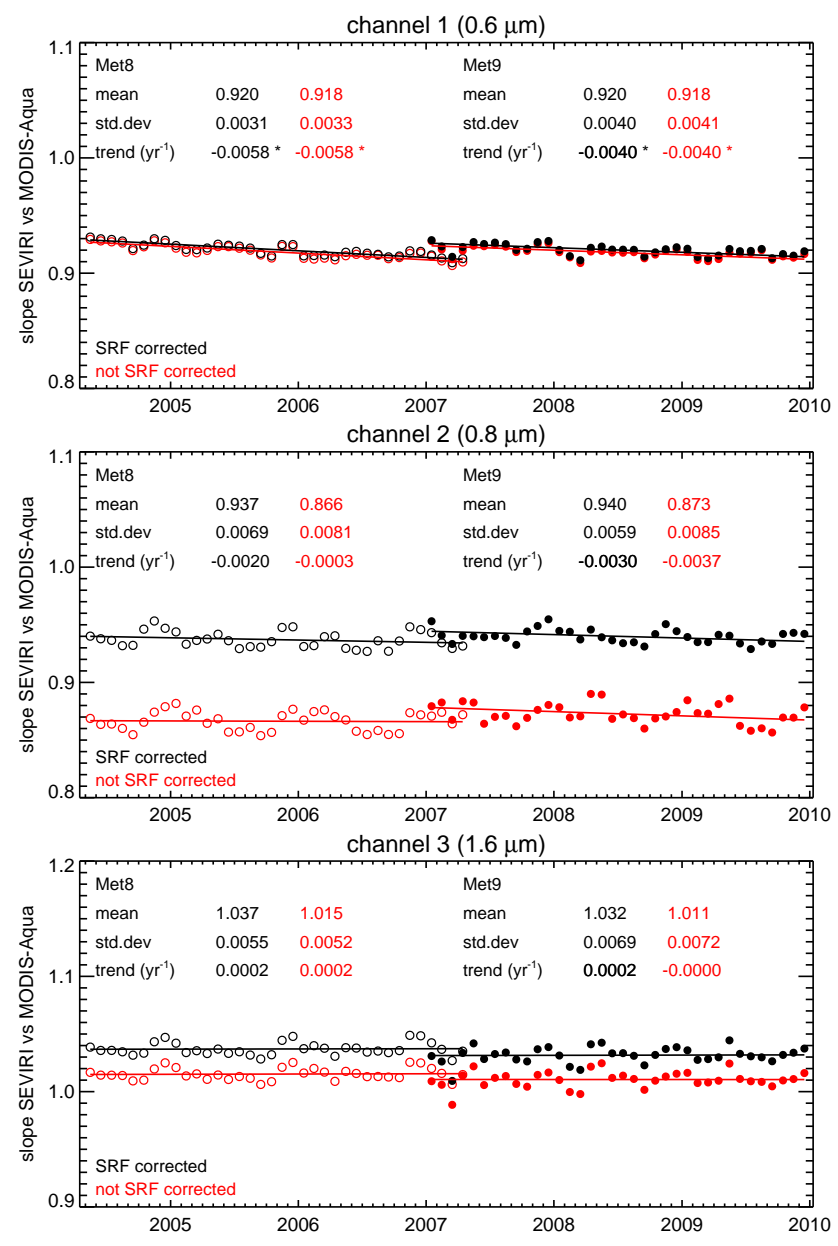

Fig. 5. Time series of inter-calibration slopes for SEVIRI-Meteosat against MODIS-Aqua for three solar channels. The open circles are the monthly slopes for Meteosat-8, while the filled circles are for Meteosat-9. The solid lines are linear fits through those monthly slopes. Black symbols and lines correspond to data that have been corrected for SRF differences, while red symbols and lines correspond to data that have not been corrected for SRF differences. Mean, standard deviation (relative to the trend line), and trend of the inter-calibration slopes are indicated in the plots. Trends that are significant at the $95 \%$ level are marked by an asterisk.

that is observed. On average, over all the scenes analysed here, the respective SRFs lead to about $7 \%$ difference in reflectance. Thus, the inter-calibration slope is enhanced from about 0.87 to 0.94 after SRF correction. The final result is that operational EUMETSAT-SEVIRI reflectances in channel 2 are about $6 \%$ too low as compared to MODIS-Aqua. It is encouraging to see that the standard deviation of monthly slopes is reduced after SRF correction, although it is still larger than for channel 1. This is another indication that the correction method works well. A seasonal cycle in derived inter-calibration slopes is present for channel 2. This may point to imperfections in the accounting for water vapour variability. However, since a slight seasonal cycle is also 
observed for channel 1 , other factors must play a role as well. A hypothesis would be that a seasonally varying amount of bright clouds leads to a variation of the dynamic range of reflectance, but such a variation was not observed. We speculate that the seasonal cycle is somehow related to the sampling of varying parts of the Bidirectional Reflection Distribution Functions (BRDFs). For channel 3 the magnitude of the SRF correction is both smaller and less variable over time as compared to channel 2 . The lower variability is explained by the fact that the main absorbing gases in channel $3\left(\mathrm{CO}_{2}\right.$ and $\mathrm{CH}_{4}$ ) have nearly constant concentrations. For this channel the EUMETSAT-SEVIRI reflectance is found to be $3.5 \%$ too high.

The inter-calibration slopes for Meteosat- 8 and Meteosat9 are nearly identical for all channels, demonstrating that the operational vicarious calibration performed at EUMETSAT is consistent between both satellites. In Fig. 5 the trends of the inter-calibration slopes are also shown. The annual trend is in all cases much smaller than $1 \%$ per year. We have calculated the uncertainty of the trends following Weatherhead et al. (1998). Only the trends for channel 1 (both Meteosats) are significant at the $95 \%$ level, indicating a slow degradation of this SEVIRI channel compared to MODIS-Aqua. Overall, the results demonstrate that the SEVIRI instrument behaves very stable over time.

\section{Sensitivity analysis of pixel selection}

In this section, we elaborate on the robustness of the regression statistics to various underlying choices regarding selection and sampling of pixels. Fit statistics for monthly SEVIRI-MODIS regressions for the years 2007-2009 are shown in Table 2. As outlined before, the "standard" configuration contains all pixels with $\Delta \theta_{0}<10^{\circ}, \Delta \theta<10^{\circ}$, and $\Delta \Theta<10^{\circ}$, as well as an $R_{\mathrm{n}}$ upper limit of 0.6 for channel 2. Results are shown for channel 1 but are similar for the other channels, except for a few cases which are included in Table 2.

First, the sensitivity to the matching of viewing angles is evaluated. If no limit to the viewing angle difference is set, poor regressions are obtained. The correlation coefficients are lower than for the standard case (on average 0.967 vs. 0.991), and there is a considerable difference between linear fits forced through the origin and free linear fits. The resulting mean inter-calibration slope is $3 \%$ smaller than with the standard selection criteria. Subsequent analyses with looser and stricter matching criteria for the viewing angle difference $\left(\Delta \theta<20^{\circ}\right.$ and $\Delta \theta<5^{\circ}$, respectively) indicate that the results are not critically dependent on the exact limit. The matching of scattering angles is found to be less important. If the $\Delta \Theta$ criterion is not applied, similar slopes are obtained, but their monthly variability is higher and the mean correlation coefficients is lower than in the standard configuration.
In addition to ray-matching criteria, it might be important to avoid geometries for which reflectance is a fast-varying function of the scattering angle for particular scenes. We tested the following selection criteria:

$-\Theta<135^{\circ}$ or $\Theta>145^{\circ}$, to avoid the cloud bow;

- $\Theta<170^{\circ}$, to avoid the backscatter peak;

- $\Theta$ more than $25^{\circ}$ away from the glint angle, to avoid sunglint.

It turns out that application of none of these criteria makes a difference to the mean inter-calibration slope, while a positive impact on the correlation coefficients and on the standard deviation of monthly slopes is observed. However, since the respective features (e.g. the cloud bow) occur only during certain parts of the year, these additional filters lead to a larger variability in the number of grid points over the year. For satellites with different overpass times, an even larger seasonal variation of the number of data points was obtained, which deteriorated the fits. Therefore, these criteria have not been included in the standard configuration.

The impact of the horizontal resolution at which the reflectances of both instruments are aggregated is found to have no influence on the inter-calibration slopes. This is a good result, since the choice of resolution is somewhat arbitrary. Different resolutions do yield slightly different correlation coefficients, with consistently higher correlations at lower resolutions, which is partly a consequence of a lower sensitivity to navigation errors.

Next, the impact of the amount of data is evaluated by keeping data from only one out two, four, or eight days in the regressions. It turns out that even with approximately weekly data the same mean inter-calibration coefficient is obtained, although the standard deviation of monthly slopes becomes larger.

We also investigated what happens if radiances below or above a certain limit are neglected. It turns out that neither setting a lower limit to $R_{\mathrm{n}}$ of 0.1 nor an upper limit of 0.5 has significant impact on the channel-1 calibration slopes. Nevertheless, a drop in the correlation coefficients is observed, which might be attributed to the decreased dynamic range of radiances. Table 2 also shows the regression statistics for applying the upper $R_{\mathrm{n}}$ limit to channels 2 and 3 . For channel 2 the results are similar to the standard settings, which demonstrates that the exact value of the upper $R_{\mathrm{n}}$ limit, needed to account for the saturation of MODIS channel 2, is not very critical. Channel 3 sun-normalised radiances rarely exceed 0.5 , and therefore the number of data points and thus the fit statistics are hardly affected by applying an upper limit to $R_{\mathrm{n}}$.

In our calibration method, the albedo of observed scenes is implicitly assumed to be spectrally uniform over the various SRFs for a particular channel. While this assumption is well satisfied over ocean surfaces and clouds, land surfaces 
Table 2. Sensitivity of regression statistics ${ }^{\mathrm{a}}$ to pixel selection criteria and sampling strategies. Results are for SEVIRI-Meteosat-9 to MODISAqua fits for the years 2007-2009.

\begin{tabular}{|c|c|c|c|c|c|c|c|}
\hline & & $\bar{N}$ & $\bar{s}$ & $\overline{s_{2 p}}$ & $\sigma(s)$ & $\bar{r}$ & $100 \times \sigma(r)$ \\
\hline \multicolumn{8}{|c|}{ channel 1} \\
\hline \multirow{8}{*}{ geometric criteria } & standard settings & 54637 & 0.920 & 0.916 & 0.0040 & 0.991 & 0.23 \\
\hline & no $\Delta \theta$ criterion & 161863 & 0.888 & 0.935 & 0.0124 & 0.967 & 0.75 \\
\hline & $\Delta \theta<20^{\circ}$ & 74292 & 0.918 & 0.915 & 0.0040 & 0.991 & 0.18 \\
\hline & $\Delta \theta<5^{\circ}$ & 30682 & 0.919 & 0.915 & 0.0038 & 0.991 & 0.24 \\
\hline & no $\Delta \Theta$ criterion & 92003 & 0.920 & 0.917 & 0.0077 & 0.986 & 1.00 \\
\hline & include sunglint criterion & 34744 & 0.921 & 0.912 & 0.0028 & 0.993 & 0.12 \\
\hline & include rainbow criterion & 36147 & 0.920 & 0.913 & 0.0024 & 0.993 & 0.16 \\
\hline & include glory criterion & 53329 & 0.920 & 0.916 & 0.0038 & 0.991 & 0.27 \\
\hline \multirow{2}{*}{ spatial resolution } & low resolution $\left(0.3^{\circ}\right)$ & 13785 & 0.920 & 0.916 & 0.0040 & 0.994 & 0.23 \\
\hline & high resolution $\left(0.1^{\circ}\right)$ & 122603 & 0.919 & 0.913 & 0.0040 & 0.987 & 0.25 \\
\hline \multirow{3}{*}{ temporal sampling } & 1 of 2 days selection & 27718 & 0.921 & 0.916 & 0.0043 & 0.992 & 0.23 \\
\hline & 1 of 4 days selection & 14140 & 0.921 & 0.916 & 0.0053 & 0.991 & 0.36 \\
\hline & 1 of 8 days selection & 7197 & 0.921 & 0.916 & 0.0070 & 0.991 & 0.51 \\
\hline \multirow{2}{*}{$R_{\mathrm{n}}$ limits } & $R_{\mathrm{n}}>0.1$ & 34614 & 0.920 & 0.914 & 0.0038 & 0.988 & 0.24 \\
\hline & $R_{\mathrm{n}}<0.5$ & 51098 & 0.923 & 0.919 & 0.0057 & 0.983 & 0.56 \\
\hline \multirow{2}{*}{ surface type } & ocean only & 35055 & 0.919 & 0.917 & 0.0058 & 0.991 & 0.32 \\
\hline & land only & 18321 & 0.921 & 0.910 & 0.0040 & 0.989 & 0.22 \\
\hline \multicolumn{8}{|c|}{ channel 2} \\
\hline & standard settings & 52392 & 0.940 & 0.932 & 0.0059 & 0.986 & 0.41 \\
\hline$R_{\mathrm{n}}$ limits & $R_{\mathrm{n}}<0.5$ & 50112 & 0.937 & 0.923 & 0.0062 & 0.984 & 0.45 \\
\hline \multirow{2}{*}{ surface type } & ocean only & 33857 & 0.951 & 0.940 & 0.0077 & 0.983 & 0.89 \\
\hline & land only & 17369 & 0.932 & 0.962 & 0.0061 & 0.967 & 1.00 \\
\hline \multicolumn{8}{|c|}{ channel 3} \\
\hline & standard settings & 54640 & 1.032 & 1.028 & 0.0069 & 0.988 & 0.53 \\
\hline$R_{\mathrm{n}}$ limits & $R_{\mathrm{n}}<0.5$ & 54304 & 1.032 & 1.028 & 0.0072 & 0.987 & 0.60 \\
\hline \multirow{2}{*}{ surface type } & ocean only & 35062 & 1.033 & 1.031 & 0.0165 & 0.977 & 1.96 \\
\hline & land only & 18317 & 1.030 & 1.016 & 0.0057 & 0.984 & 0.45 \\
\hline
\end{tabular}

are often characterised by a spectrally varying albedo. To test the impact of this variability, we repeat the regressions for ocean-only and land-only pixel selections. The fit statistics for channel 1 are virtually the same for the ocean-only and land-only selections compared to the standard configuration. For channel 2 larger differences are found: if only ocean pixels are considered, the inter-calibration slope increases by $1.1 \%$, and if only land pixels are considered, the slope decreases by $0.8 \%$. In particular for the land selection, also the correlation coefficient decreases and becomes more variable. For channel 3 the selection of land or ocean pixels has negligible impact on the inter-calibration slopes. However, for the ocean selection a considerably higher standard deviation of the slopes as well as a lower and more variable correlation coefficient is obtained, suggesting that these ocean-only fits are somehow less robust than the standard fits.

In summary, the sensitivity study shows that results of the inter-calibration regressions are very robust and not critically dependent on the chosen selection and sampling strategy, although it is clear that certain limits to the viewing zenith angle and scattering angle differences need to be applied. The largest sensitivity is found for the restriction to scenes over ocean or land for channel 2. Based on these results, we can try to come up with uncertainty estimates of the derived inter-calibration slopes based on the sensitivity to pixel selection and sampling criteria as well as the standard deviation of monthly slopes from Table 2 . This yields conservative estimates of $1 \%$ for channel 1 , and $1.5 \%$ for channels 2 and 3 . It needs to be emphasised that these estimates exclude 
potential systematic components such as errors in the SRF correction method (e.g. biases in $H_{\mathrm{c}}$ or TCWV), uncertainties in the spectral response functions or the SEVIRI solar constant, and the MODIS calibration uncertainty.

\section{Polar imager inter-calibration}

Our method for the inter-calibration of MODIS-Aqua and SEVIRI can be applied to any other polar-orbiting imager than MODIS-Aqua with shortwave channels corresponding to those of SEVIRI. This is not of direct interest, but allows indirectly to inter-calibrate these other polar-orbiting imagers with MODIS-Aqua, as will be demonstrated below.

First we show, as an example, inter-calibration results between AVHRR onboard NOAA-17 and SEVIRI for the period 2007 to 2009 in Fig. 6. For AVHRR the reference calibration coefficients are taken from Heidinger et al. (2010). SEVIRI channel-1 reflectances, based on the EUMETSAT calibration, are about $6 \%$ lower than AVHRR, and the SRF correction has very little effect. In contrast, for channel 2 the impact of SRF correction is very large (almost 7\%), because the AVHRR channel is much broader than its SEVIRI counterpart, and is much more affected by atmospheric water vapour absorption. The final result is that SEVIRI channel-2 reflectances are $2.5 \%$ lower than AVHRR. It is encouraging to see that the standard deviation of intercalibration slopes is more than halved by the SRF correction. The $1.6 \mu \mathrm{m}$ channels, although they are quite different on AVHRR and SEVIRI, are on average similarly impacted by trace gas absorption. Hence, SRF correction has little effect. Averaged over the years 2007 to 2009, SEVIRI and AVHRR channel-3 reflectances are almost at the same level, but there is a large and significant trend of about $1.5 \%$ per year in the inter-calibration slopes. An analogous sensitivity study as in Sect. 5 was carried out for the AVHRR-SEVIRI inter-calibration, giving very similar results as for MODISSEVIRI. In particular, land-only and ocean-only pixel selections yielded inter-calibration slopes that differed less than $1 \%$ from the slopes obtained from both land and ocean pixels for all channels. This indicates again that the impact of spectrally varying surface albedo is modest.

When two polar imagers ( $\mathrm{P} 1$ and $\mathrm{P} 2$ ) have been compared to SEVIRI, it is straightforward to inter-calibrate these polar imagers by taking the ratio of the respective inter-calibration slopes:

$s_{\mathrm{P} 1 / \mathrm{P} 2}=\frac{s_{\mathrm{SEV} / \mathrm{P} 2}}{s_{\mathrm{SEV} / \mathrm{P} 1}}$.

A similar strategy was applied by Wang et al. (2011), who inter-calibrated infrared radiances from the Atmospheric Infrared Sounder (AIRS) and the Infrared Atmospheric Sounding Interferometer (IASI) using the Geostationary Operational Environmental Satellite (GOES) as a transfer instrument. With this so called double differencing approach they
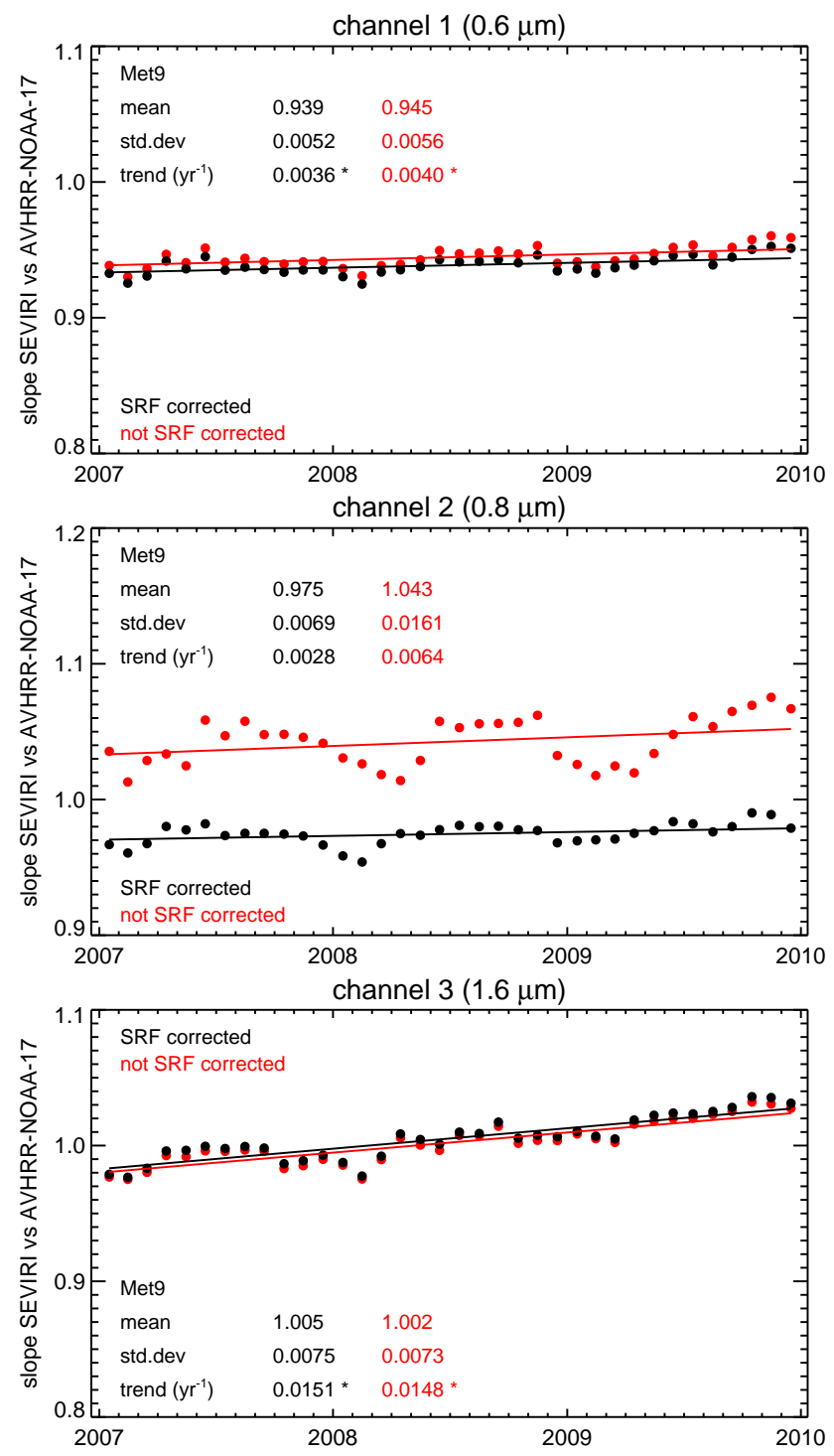

Fig. 6. Same as Fig. 5, but for AVHRR-NOAA17 instead of MODIS-Aqua, and for Meteosat-9 only.

were able to verify an inter-calibration based on direct AIRSIASI SNOs. Because it is natural to analyse ratios of reflectances as opposed to differences in brightness temperatures, Eq. (8) has the shape of a "double ratio" instead of the double difference applied in Wang et al. (2011).

With Eq. (8), i.e. using SEVIRI as a transfer instrument, we inter-calibrated MODIS-Terra and the AVHRRs on NOAA-17 and NOAA-18 with respect to MODIS-Aqua for the years 2007 to 2009 . Time series of resulting intercalibration slopes are presented in Fig. 7. The two MODIS instruments are found to be very consistent. For channel 1 a difference of about $2 \%$ is obtained, Terra having lower reflectances than Aqua. A similar difference was reported by Minnis et al. (2008) and Wu et al. (2013). The 0.8 and $1.6 \mu \mathrm{m}$ MODIS channels on Aqua and Terra differ less than $1 \%$. A 

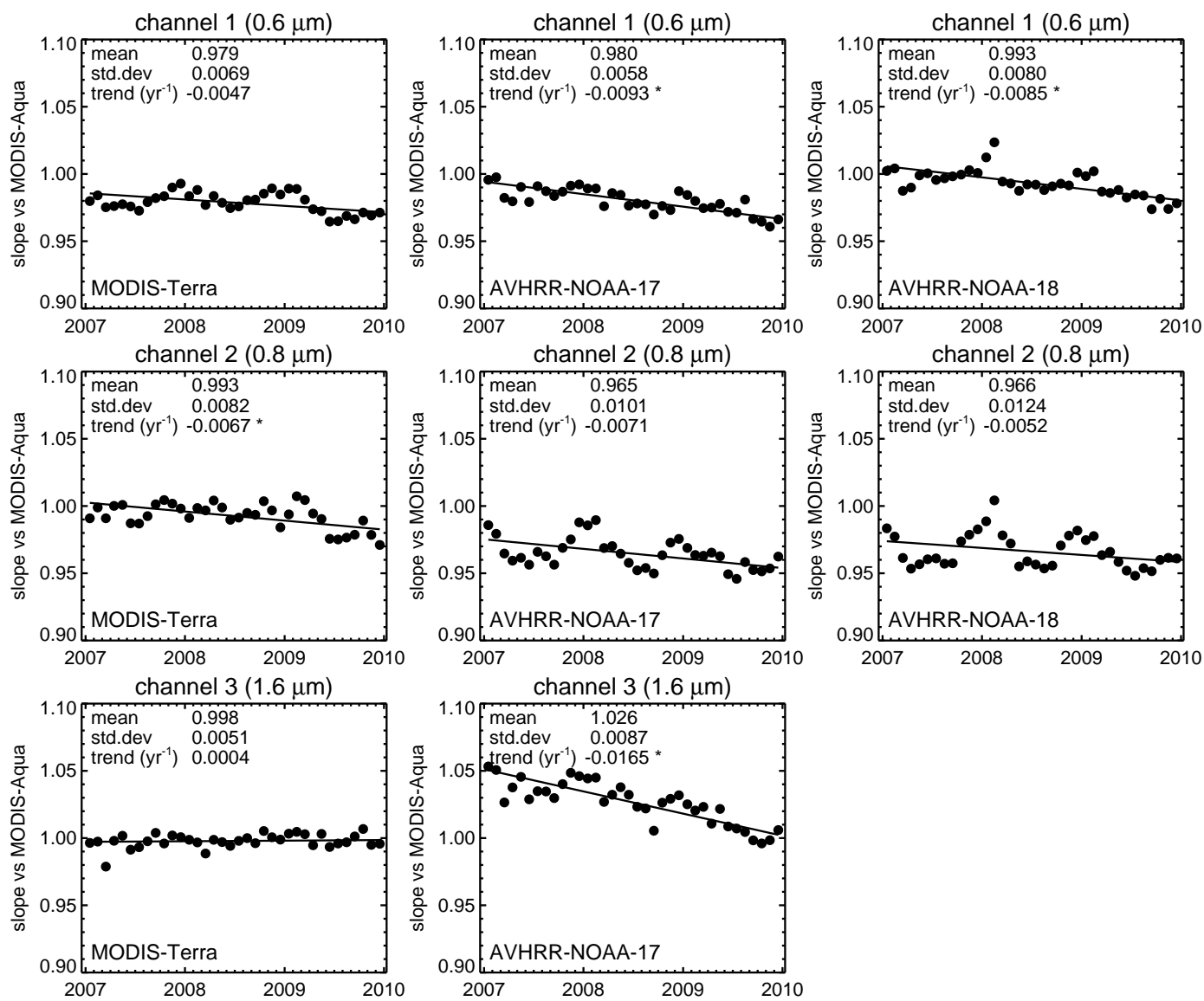

Fig. 7. Time series of inter-calibration slopes of polar-orbiting imagers against MODIS-Aqua using SEVIRI-Meteosat-9 as a transfer instrument. Results are shown for MODIS-Terra (left column), AVHRR-NOAA-17 (middle column) and AVHRR-NOAA-18 (right column) and channels around $0.6 \mu \mathrm{m}$ (top row panels), $0.8 \mu \mathrm{m}$ (middle row panels) and $1.6 \mu \mathrm{m}$ (bottom row panels). Note that the $1.6 \mu \mathrm{m}$ channel was not active on AVHRR-NOAA-18. Mean, standard deviation (relative to the trend line), and trend of the inter-calibration slopes are indicated in the plots. Trends that are significant at the $95 \%$ level are marked by asterisks.

significant negative trend is calculated for Terra channel 2. There is a clear hint, though, for a break in the time series around May-June 2009, when Terra/Aqua inter-calibration slopes appear to decrease by around $1 \%$ for all channels. A drop in MODIS-Terra reflectances in 2009 was also identified by Wu et al. (2013) as being due to a one-time calibration correction.

The AVHRR channel- 1 reflectances are on average about 2 and $1 \%$ lower than MODIS-Aqua for NOAA-17 and NOAA-18, respectively. In addition, negative trends of around $0.9 \%$ per year are observed, which is slightly larger than the 95-\% significance level. AVHRR channel-2 reflectances are found to be $3.5 \%$ too low compared to MODIS-Aqua. The inter-calibration slopes are also more variable than for other channels. For channel 3, which is only active on NOAA-17, AVHRR is found to overestimate reflectances by $2.5 \%$ on average, with a significant negative trend of $1.6 \%$ per year.

The Heidinger AVHRR calibration relies on direct SNOs with MODIS, and its accuracy was estimated to be 2 and
$3 \%$ for channels 1 and 2, respectively (Heidinger et al., 2010). Thus, although the deviations obtained here are on average close to that accuracy, this is not the case during the full 2007-2009 time period. The average offsets and temporal trends in Fig. 7 point to inconsistencies between both calibration methods. These may result from different approaches to SRF correction in combination with different atmospheric composition and scene types at the sampling locations, i.e. high latitudes for the direct SNOs versus low latitudes in the present study. However, the SRF correction is negligible for channel 1 and small for channel 3, so the differences cannot be solely explained by the SRF correction approach. In addition, such differences should not lead to temporal trends. An explanation for the trend in AVHRR NOAA17 channel-3 reflectances could be its orbital drift of more than an hour from 2007 to 2009 , leading to a positive trend in solar zenith angles. However, it is unclear why this would affect channel 3 so much more than channels 1 and 2. The negative trend of, in particular, the AVHRR $1.6 \mu \mathrm{m}$ channel 
thus remains puzzling, and requires further research to be elucidated.

\section{Conclusions}

In this study, we have calibrated the solar channels of the geostationary SEVIRI instrument on MSG with MODIS on Aqua. The inter-calibration was based on regressions of collocated reflectances. Differences in spectral response between the instrument channels were corrected for by tabulated radiative transfer calculations of the effect of trace gas absorption on top-of-atmosphere reflectance. SEVIRI operational reflectances were found to be quite stable during the years 2004-2009, but considerably biased with respect to MODIS: $-8,-6$, and $+3.5 \%$ for channels $1(0.6 \mu \mathrm{m}), 2$ $(0.8 \mu \mathrm{m})$, and $3(1.6 \mu \mathrm{m})$, respectively. A sensitivity study revealed that the derived inter-calibration coefficients do not critically depend on various choices regarding pixel selection, as long as the viewing and illumination geometry of the two instruments is matched. Importantly, the potential effect of spectrally varying surface reflectance, which was not accounted for in our SRF correction, was investigated by performing inter-calibrations based on land-only and oceanonly pixel selections. This led to deviations in the slopes of less than $1.1 \%$. Based on the sensitivity study, we estimated uncertainties in the inter-calibration slopes to be $1 \%$ for channel 1 and $1.5 \%$ for channels 2 and 3. It should be noted that these estimates exclude potential systematic errors in the calibration procedure (e.g. related to SRF correction) and the uncertainty of the Aqua-MODIS calibration. Interestingly, the channel-3 inter-calibration did not seem to be affected by the significant number of defective detectors in the corresponding MODIS-Aqua $1.6 \mu \mathrm{m}$ channel. Although not attempted in this study, the inter-calibration method should also be applicable to broadband channels, such as SEVIRI's HRV channel, albeit with a larger uncertainty related to SRF correction.

Using double differencing (see Eq. 8), our method was applied for the inter-calibration of other polar imagers with Aqua-MODIS for the years 2007-2009. Here, SEVIRI served as a calibration transfer instrument. This analysis demonstrated that Terra-MODIS channel 1 has a bias of about $-2 \%$ compared to Aqua, while other channels are unbiased. The AVHRR instruments on NOAA-17 and NOAA18 were also investigated using the direct AVHRR-MODIS SNO based calibration by Heidinger et al. (2010) as a reference. We found reasonable agreement for channel 1, with a mean AVHRR-MODIS reflectance difference below $2 \%$ and a just-significant negative trend. For channels 2 and 3 the differences were larger $(-3.5$ and $+2.5 \%$, respectively) and AVHRR channel-3 reflectances had a negative trend of more than $1.5 \%$ per year. Overall, this indicates that the methods used by Heidinger et al. (2010) and in the present study yield reasonably consistent results but there are differences that require further investigation.

The approach for inter-calibration of polar-orbiting imagers using the geostationary SEVIRI as a transfer instrument has the advantage of daily availability of collocated reflectances. Since both clear and cloudy pixels are used, a large dynamic range of reflectances is obtained and robust statistics can be developed. The method allows verifying calibrations based on polar-polar SNOs, which typically occur at high latitudes only. An obvious limitation of the method is that a geostationary sensor with the appropriate solar channels is required, which reduces the applicability backward in time. With the SEVIRI record already spanning almost ten years and a similar time period to come, and with the upcoming Meteosat Third Generation as well as other new geostationary imagers, the applicability of the method is guaranteed in the far future, for even more channels than used in this study.

The results presented here have been and will be used for the generation of consistent long-term cloud property datasets in EUMETSAT's Satellite Application Facility on Climate Monitoring (CM-SAF) and ESA's Climate Change Initiative on Clouds (Cloud_CCI). Future plans include the extension of the inter-calibration results to longer time series, making use of the latest (Collection 6) MODIS calibration as a reference.

Acknowledgements. This work was partly funded by EUMETSAT's CM-SAF and ESA's Cloud_CCI projects. The authors would like to thank Dave Doelling, Andrew Heidinger, Karl-Göran Karlsson, and Phil Watts for fruitful discussions.

Edited by: B. Mayer

\section{References}

Anderson, G. P., Berk, A., Acharya, P. K., Matthew, M. W., Bernstein, L. S., Chetwynd, J. H., Dothe, H., Adler-Golder, S. M., Ratkowski, A. J., Felde, G. W., Gardner, J. A., Hoke, M. L., Richtsmeier, S. C., and Jeong, L. S.: MODTRAN4 version 2: radiative transfer modeling, Proc. SPIE, 4381, 455-459, doi:10.1117/12.437035, 2001.

Cao, C., Xiong, X., Wu, A., and Wu, X.: Assessing the consistency of AVHRR and MODIS L1B reflectance for generating fundamental climate data records, J. Geophys. Res., 113, D09114, doi:10.1029/2007JD009363, 2008.

Dee, D. P., Uppala, S. M., Simmons, A. J., Berrisford, P., Poli, P., Kobayashi, S., Andrae, U., Balmaseda, M. A., Balsamo, G., Bauer, P., Bechtold, P., Beljaars, A. C. M., van de Berg, L., Bidlot, J., Bormann, N., Delsol, C., Dragani, R., Fuentes, M., Geer, A. J., Haimberger, L., Healy, S. B., Hersbach, H., Hólm, E. V., Isaksen, L., Kallberg, P., Köhler, M., Matricardi, M., McNally, A. P., Monge-Sanz, B. M., Morcrette, J.-J., Park, B.K., Peubey, C., de Rosnay, P., Tavolato, C., Thépaut, J.-N., and Vitart, F.: The ERA-Interim reanalysis: configuration and 
performance of the data assimilation system, Q. J. Roy. Meteorol. Soc., 137, 553-597, doi:10.1002/qj.828, 2011.

Doelling, D. R., Nguyen, L., and Minnis, P.: Calibration comparisons between SEVIRI, MODIS, and GOES data, in: Proceedings of the 2004 EUMETSAT Meteorological Satellite Conference, Prague, Czech Republic, 2004.

Doelling, D. R., Morstad, D., Scarino, B. R., Bhatt, R., and Gopalan, A.: The characterization of deep convective clouds as an invariant calibration target and as a visible calibration technique, IEEE T. Geosci. Remote, 51, 1147-1159, doi:10.1109/TGRS.2012.2225066, 2013a.

Doelling, D. R., Scarino, B. R., Morstad, D., Gopalan, A., Bhatt, R., Lukashin, C., and Minnis, P.: The intercalibration of geostationary visible imagers using operational hyperspectral SCIAMACHY radiances, IEEE T. Geosci. Remote, 51, 1245-1254, doi:10.1109/TGRS.2012.2227760, 2013b.

Goldberg, M., Ohring, G., Butler, J., Cao, C., Datla, R., Doelling, D., Gärtner, V., Hewison, T., Iacovazzi, B., Kim, D., Kurino, T., Lafeuille, J., Minnis, P., Renaut, D., Schmetz, J., Tobin, D., Wang, L., Weng, F., Wu, X., Yu, F., Zhang, P., and Zhu, T.: The global space-based inter-calibration system, B. Am. Meteorol. Soc., 92, 467-475, doi:10.1175/2010BAMS2967.1, 2011.

Govaerts, Y. M. and Clerici, M.: Evaluation of radiative transfer simulations over bright desert calibration sites, IEEE T. Geosci. Remote, 42, 176-187, doi:10.1109/TGRS.2003.815406, 2004.

Govaerts, Y. M., Clerici, M., and Clerbaux, N.: Operational calibration of the Meteosat radiometer VIS band, IEEE T. Geosci. Remote, 42, 1900-1914, doi:10.1109/TGRS.2004.831882, 2004.

Ham, S.-H. and Sohn, B. J.: Assessment of the calibration performance of satellite visible channels using cloud targets: application to Meteosat-8/9 and MTSAT-1R, Atmos. Chem. Phys., 10, 11131-11149, doi:10.5194/acp-10-11131-2010, 2010.

Heidinger, A. K., Cao, C., and Sullivan, J. T.: Using Moderate Resolution Imaging Spectrometer (MODIS) to calibrate advanced very high resolution radiometer reflectance channels, J. Geophys. Res., 107, 4702-1249, doi:10.1029/2001JD002035, 2002.

Heidinger, A. K., Sullivan, J. T., and Rao, C. R. N.: Calibration of visible and near-infrared channels of the NOAA-12 AVHRR using time series of observations over deserts, Int. J. Remote Sens., 24, 3635-3649, doi:10.1080/0143116021000023907, 2003.

Heidinger, A. K., Straka III, W. C., Molling, C. C., Sullivan, J. T., and $\mathrm{Wu}, \mathrm{X}$.: Deriving an inter-sensor consistent calibration for the AVHRR solar reflectance data record, Int. J. Remote Sens., 31, 6493-6517, doi:10.1080/01431161.2010.496472, 2010.

McClatchey, R. A., Fenn, R. W., Selby, J. E. A., Volz, F. E., and Garing, J. S.: Optical properties of the atmosphere, Tech. Rep. ARCRL-71-0279, Air Force Geophysics Laboratory, Bedford, MA, USA, 1971.

Meirink, J. F., Roebeling, R. A., and Stammes, P.: Atmospheric correction for the KNMI Cloud Physical Properties retrieval algorithm, Tech. Rep. TR-304, KNMI, De Bilt, the Netherlands, 2009.
Minnis, P., Nguyen, L., Doelling, D. R., Young, D. F., Miller, W. F., and Kratz, D. P.: Rapid calibration of operational and research meteorological satellite imagers, Part 1: evaluation of research satellite visible channels as references, J. Atmos. Ocean. Tech., 19, 1233-1249, 2002.

Minnis, P., Doelling, D. R., Nguyen, L., Miller, W. F., and Chakrapani, V.: Assessment of the visible channel calibrations of the VIRS on TRMM and MODIS on Aqua and Terra, J. Atmos. Ocean. Tech., 25, 385-400, doi:10.1175/2007JTECHA1021.1, 2008.

Roebeling, R. A. and Holleman, I.: SEVIRI rainfall retrieval and validation using weather radar observations, J. Geophys. Res., 114, D21202, doi:10.1029/2009JD012102, 2009.

Roebeling, R. A., Feijt, A. J., and Stammes, P.: Cloud property retrievals for climate monitoring: implications of differences between SEVIRI on METEOSAT-8 and AVHRR on NOAA-17, J. Geophys. Res., 111, D20210, doi:10.1029/2005JD006990, 2006.

Smith, D. L., Mutlow, C. T., and Rao, C. R. N.: Calibration monitoring of the visible and near-infrared channels of the Along-Track Scanning Radiometer-2 by use of stable terrestrial sites, Appl. Optics, 41, 515-523, doi:10.1364/AO.41.000515, 2002.

van $\operatorname{der}$ A, R. J., Allaart, M. A. F., and Eskes, H. J.: Multi sensor reanalysis of total ozone, Atmos. Chem. Phys., 10, 11277-11294, doi:10.5194/acp-10-11277-2010, 2010.

Vermote, E. F. and Kaufman, Y. J.: Absolute calibration of AVHRR visible and near-infrared channels using ocean and cloud views, Int. J. Remote Sens., 16, 2317-2340, doi:10.1080/01431169508954561, 1995.

Wang, L., Goldberg, M., Wu, X., Cao, C., Iacovazzi Jr., R. A., Yu, F., and Li, Y.: Consistency assessment of Atmospheric Infrared Sounder and Infrared Atmospheric Sounding Interferometer radiances: double differences versus simultaneous nadir overpasses, J. Geophys. Res., 116, D11111, doi:10.1029/2010JD014988, 2011.

Weatherhead, E. C., Reinsel, G. C., Tiao, G. C., Meng, X.-L., Choi, D., Cheang, W.-K., Keller, T., DeLuisi, J., Wuebbles, D. J., Kerr, J. B., Miller, A. J., Oltmans, S. J., and Frederick, J. E.: Factors affecting the detection of trends: statistical considerations and applications to environmental data, J. Geophys. Res., 103, 17149-17161, 1998.

Wu, A., Xiong, X., Doelling, D. R., Morstad, D., Angal, A., and Bhatt, R.: Characterization of Terra and Aqua MODIS VIS, NIR, and SWIR spectral bands' calibration stability, IEEE T. Geosci. Remote, 51, 4330-4338, doi:10.1109/TGRS.2012.2226588, 2013.

Xiong, X. and Barnes, W.: An overview of MODIS radiometric calibration and characterization, Adv. Atmos. Sci., 23, 69-79, 2006.

Xiong, X., Sun, J., Wu, A., Chiang, K.-F., Esposito, J., and Barnes, W.: Terra and Aqua MODIS calibration algorithms and uncertainty analysis, Proc. SPIE, 5978, 59780V, doi:10.1117/12.627631, 2005. 